\title{
Brain White Matter Development Is Associated with a Human-Specific Haplotype Increasing the Synthesis of Long Chain Fatty Acids
}

\author{
Bart D. Peters, ${ }^{1}$ Aristotle N. Voineskos, ${ }^{2,3,4}$ Philip R. Szeszko, ${ }^{1,5}$ Tristram A. Lett, ${ }^{2,3}$ Pamela DeRosse, ${ }^{1,5}$ Saurav Guha, ${ }^{1}$ \\ Katherine H. Karlsgodt, ${ }^{1,5}$ Toshikazu Ikuta, ${ }^{6}$ Daniel Felsky, ${ }^{2,3}$ Majnu John, ${ }^{1,5}$ David J. Rotenberg, ${ }^{2}$ James L. Kennedy, ${ }^{2,3,4}$ \\ Todd Lencz ${ }^{1,5}$ and Anil K. Malhotra ${ }^{1,5}$ \\ ${ }^{1}$ Division of Psychiatry Research, Zucker Hillside Hospital, Glen Oaks, New York 11004, ${ }^{2}$ Campbell Family Mental Health Institute, Centre for Addiction and \\ Mental Health, Toronto, Ontario M5T 1R8, Canada, ${ }^{3}$ Institute of Medical Science, University of Toronto, Toronto, Ontario M5S 1A8, Canada, ${ }^{4}$ Department \\ of Psychiatry, University of Toronto, Toronto, Ontario M5T 1R8, Canada, ${ }^{5}$ Center for Psychiatric Neuroscience, Feinstein Institute for Medical Research, \\ Manhasset, New York 11030, and ${ }^{6}$ Department of Communication Sciences and Disorders, School of Applied Sciences, University of Mississippi, \\ University, Mississippi 38766
}

The genetic and molecular pathways driving human brain white matter (WM) development are only beginning to be discovered. Long chain polyunsaturated fatty acids (LC-PUFAs) have been implicated in myelination in animal models and humans. The biosynthesis of LC-PUFAs is regulated by the fatty acid desaturase (FADS) genes, of which a human-specific haplotype is strongly associated with $\omega-3$ and $\omega-6$ LC-PUFA concentrations in blood. To investigate the relationship between LC-PUFA synthesis and human brain WM development, we examined whether this FADS haplotype is associated with age-related WM differences across the life span in healthy individuals 9-86 years of age $(n=207)$. Diffusion tensor imaging was performed to measure fractional anisotropy (FA), a putative measure of myelination, of the cerebral WM tracts. FADS haplotype status was determined with a single nucleotide polymorphism (rs174583) that tags this haplotype. Overall, normal age-related WM differences were observed, including higher FA values in early adulthood compared with childhood, followed by lower FA values across older age ranges. However, individuals homozygous for the minor allele (associated with lower LC-PUFA concentrations) did not display these normal age-related WM differences (significant age $\times$ genotype interactions, $p_{\text {corrected }}<0.05$ ). These findings suggest that LC-PUFAs are involved in human brain WM development from childhood into adulthood. This haplotype and LC-PUFAs may play a role in myelin-related disorders of neurodevelopmental origin.

Key words: brain development; diffusion tensor imaging; fatty acid desaturase genes; myelin; polyunsaturated fatty acids; white matter

\section{Introduction}

Expansion of prefrontal white matter (WM) has likely been a critical event in human evolution (Schoenemann et al., 2005). Accordingly, prefrontal WM development is associated with development of higher-order cognitive functions (Brauer et al.,

Received June 23, 2013; revised March 2, 2014; accepted March 23, 2014.

Author contributions: B.D.P., A.N.V., P.R.S., J.L.K., T.L., and A.K.M. designed research; B.D.P., A.N.V., and P.D. performed research; B.D.P., A.N.V., P.R.S., T.A.L., S.G., K.H.K., T.I., D.F., M.J., D.J.R., and T.L. analyzed data; B.D.P., A.N.V., P.R.S., P.D., T.L., and A.K.M. wrote the paper.

This work was supported in part by the National Institutes of Health Grant R01 MH076995 to P.R.S., Grant R01 MH099167 to A.N.V., the North Shore-Long Island Jewish Health System Research Institute General Clinical Research Center (M01 RR018535), an Advanced Center for Intervention and Services Research (P30 MH090590), and a Center for Intervention Development and Applied Research (P50 MH080173) to A.K.M. This work was supported in part by the Canadian Institutes of Health Research (A.N.V.), the Dana Foundation (P.R.S.), the Brain and Behavior Research Foundation (A.N.V.), Ontario Mental Health Foundation (A.N.V.), the CAMH, and the CAMH Foundation, thanks to the Kimel Family, Koerner New Scientist Award, and Paul E. Garfinkel New Investigator Catalyst Award.

A.K.M. has received compensation from Eli Lilly, Schering-Plough/Merck, Sunovion Pharmaceuticals, Genomind, Shire, and Abbott. J.L.K. has received honoraria from Novartis, Roche, and Eli Lilly. B.D.P. has received compensation from ProPhase. The remaining authors declare no competing financial interests.

Correspondence should be addressed to Dr. Bart D. Peters, Zucker Hillside Hospital, North Shore-LIJ Health System, 75-59 263rd Street, Glen 0aks, NY 11004. E-mail: BPeters1@NSHS.edu.

DOI:10.1523/JNEUROSCI.2818-13.2014

Copyright $\odot 2014$ the authors $\quad 0270-6474 / 14 / 346367-10 \$ 15.00 / 0$
2011; Peters et al., 2012), and aberrant trajectories of prefrontal WM development have been implicated in the pathophysiology of psychiatric disorders (Gogtay et al., 2008; Paus et al., 2008).

WM microstructure, as inferred from diffusion tensor imaging (DTI), is under genetic control in childhood and early adulthood (Brouwer et al., 2010; Chiang et al., 2011), and several genes have been related to WM microstructure and volume in healthy individuals (McIntosh et al., 2008; Lencz et al., 2010; Braskie et al., 2012; Lett et al., 2013). These genes generally control poorly understood or highly complex molecular pathways that complicate deeper investigation of how these genes affect WM.

The fatty acid desaturase (FADS) gene cluster, in contrast, regulates the synthesis of well-characterized molecular targets that may play a role in myelination: $\omega-3$ and $\omega-6$ long-chain polyunsaturated fatty acids (LC-PUFAs) (Selivonchick and Johnston, 1975; Trapp and Bernsohn, 1978; Bourre et al., 1984; Martínez and Mougan, 1998; Nordvik et al., 2000; Salvati et al., 2008), with most effects being observed for $\omega$-3 LC-PUFAs. The FADS gene cluster controls the biosynthesis of $\omega-3$ and $\omega$-6 LC-PUFAs by controlling the desaturations of their precursors. The ratelimiting enzymes $\Delta-5$ and $\Delta-6$ FADS are encoded by the FADS1 
and FADS2 genes, respectively, located in a cluster on chromosome 11 (11q12-13.1). A major haplotype spanning these genes has been associated with $24 \%$ higher plasma levels of docosahexaenoic acid (DHA, an $\omega$-3 LC-PUFA) and 43\% higher levels of arachidonic acid (AA, an $\omega$-6 LC-PUFA) (Ameur et al., 2012). Intriguingly, this haplotype appears to have emerged during human evolution well after the split from the common ancestor of humans and chimpanzees (Ameur et al., 2012), which may suggest it played a role in human brain evolution (Crawford et al., 1999).

Considering the above, we hypothesized that the humanspecific FADS haplotype (Ameur et al., 2012) is associated with brain WM development in healthy humans. Such a relationship could have implications for neuropsychiatric disorders of neurodevelopmental origin, in which WM abnormalities have been implicated, such as schizophrenia and bipolar disorder (Mahon et al., 2010; Walterfang et al., 2011). Interestingly, LC-PUFA deficiencies are also well documented in these disorders (McNamara et al., 2010; Hoen et al., 2013; van der Kemp et al., 2012), which raises the intriguing possibility that their WM abnormalities are related to LC-PUFA deficiencies. In support of such a relationship, we found strong correlations between brain WM microstructure and blood concentrations of $\omega-3$ and $\omega-6$ LCPUFAs in first-episode schizophrenia patients (Peters et al., 2009, 2013).

We hypothesized that individuals homozygous for the FADS minor allele (associated with lower LC-PUFA concentrations) would not display normal age-related WM differences, as assessed using DTI, from childhood to adulthood (Peters et al., 2014). The recessive model was chosen for analysis in accordance with the observations of Ameur et al. (2012).

\section{Materials and Methods}

Participants. A total of 207 healthy whites (53\% male) between the ages of 9 and 86 years (mean \pm SD, $38.9 \pm 19.2$ years; median 35.7 years) were recruited through advertisements, word of mouth, referrals, and study registries. Written informed consent was obtained from participants or, if the participant was a minor, from a parent or guardian; all minors provided assent. Participants had no history of a current or past DSM-IV axis I major mood or psychotic disorder as assessed by structured diagnostic interview (Schedule for Affective Disorders and Schizophrenia for School-Age Children-Present and Lifetime Version) (Kaufman et al., 1997), or Structured Clinical Interview for DSM-IV disorders (First et al., 1995, 2001). IQ was estimated using the Wide Range Achievement Test 3 (Wilkinson, 1993). Participants were recruited from two sites: Zucker Hillside Hospital (ZHH), Glen Oaks, New York, and the Centre for Addiction and Mental Health (CAMH), Toronto, Ontario, Canada. Sitespecific exclusion criteria for ZHH subjects included the following: (1) intellectual or learning disability; (2) current substance abuse; and (3) significant medical illness that could affect brain structure. Site-specific exclusion criteria for CAMH subjects included the following: (1) current substance abuse (i.e., within the past 6 months), positive urine toxicology screen result, or any history of substance dependence; (2) a primary psychotic disorder in first-degree relatives; (3) previous head trauma with loss of consciousness; and (4) a neurological disorder. This study was approved by the Institutional Review Board of the North Shore-Long Island Jewish Health System and by the Centre for Addiction and Mental Health Research Ethics Board.

DTI acquisition and preprocessing. All ZHH subjects received a DTI exam at the North Shore University Medical Center (Manhasset, NY) on a GE Signa HDx 3.0 T system (General Electric Medical Systems). The sequence included volumes with diffusion gradients applied along 31 nonparallel directions $\left(b=1000 \mathrm{~s} / \mathrm{mm}^{2}\right)$ and 5 volumes without diffusion weighting $(\mathrm{TR}=14 \mathrm{~s}, \mathrm{TE}=$ minimum, matrix $=128 \times 128, \mathrm{FOV}=$ $240 \mathrm{~mm}$ ). Each volume consisted of 51 contiguous $2.5 \mathrm{~mm}$ axial slices acquired parallel to the anterior-posterior commissural line using a ramp sampled, double spin-echo, single shot echo-planar imaging method. All CAMH subjects received a DTI examination at a general hospital near CAMH using a 1.5 T GE Echospeed system (General Electric Medical Systems). The sequence included volumes with diffusion gradients applied along 23 noncollinear directions $\left(b=1000 \mathrm{~s} / \mathrm{mm}^{2}\right)$ and two volumes without diffusion weighting $(\mathrm{TR}=15 \mathrm{~s}, \mathrm{TE}=85.5 \mathrm{~ms}$, matrix $=128 \times 128$, FOV $=330 \mathrm{~mm})$. Fifty-seven slices were acquired for whole-brain coverage oblique to the axial plane $(2.6 \mathrm{~mm}$ isotropic voxels) using a spin-echo, single-shot echo-planar imaging method; the sequence was repeated three times to improve signal-to-noise ratio.

Image processing was conducted using the Functional Magnetic Resonance Imaging of the Brain Software Library (FSL; Oxford, United Kingdom; http://fsl.fmrib.ox.ac.uk/fsl). Eddy-current induced distortions and head-motion displacements were corrected through affine registration of the diffusion-weighted volumes to the first b0 volume using FSL's Linear Registration Tool (FLIRT) (Jenkinson and Smith, 2001). The b-vector table (i.e., gradient directions) for each participant was reoriented according to the registration transformation parameters. A diffusion tensor model was then fitted to the raw diffusion data at each voxel of the brain using the weighted least-squares approach in FSL's Diffusion Toolbox.

Tractography. Tractography allows segmenting anatomically valid tracts connecting specific brain regions in accordance with tracts identified macroscopically in postmortem brains, in contrast to region-ofinterest (ROI) approaches where multiple tracts may trace through one WM ROI (Mori et al., 2008). We conducted tractography of major cerebral WM tracts that could be reliably traced in each site's data and are known to show significant age effects across the life span (Voineskos et al., 2012; Peters et al., 2014): the splenium and genu of the corpus callosum (CC, which connects the bilateral occipital lobes as well as parietal and temporal cortices and the bilateral frontal lobes, respectively), inferior longitudinal fasciculus (ILF, which connects the anterior temporal lobe to the occipital lobe), inferior fronto-occipital fasciculus (IFOF, which connects the frontal lobe to the occipital lobe as well as parietal and temporal cortices), superior longitudinal fasciculus (SLF, which connects the frontal lobe to the parietal and temporal lobes), cingulum (which projects from the frontal lobe to the temporal lobe beneath the cingulate gyrus), and uncinate fasciculus (which connects the frontal lobe to the anterior temporal lobe). Established tractography procedures were used that had been optimized for the DTI data of each study site, to achieve the final common goal of segmenting the same tracts of interest for each subject. In the $\mathrm{ZHH}$ data, probabilistic tractography was performed using FSL. This tractography approach is published (Behrens et al., 2003; Peters et al., 2014) and summarized here. Within-voxel probability density functions were estimated of the principal diffusion direction using Markov Chain Monte Carlo sampling in FSL's BEDPOSTX tool (Behrens et al., 2003). A spatial probability density function was then estimated across voxels based on these local probability density functions using FSL's PROBTRACKX tool (Behrens et al., 2003), in which 5000 samples were taken for each input voxel with a 0.2 curvature threshold, $0.5 \mathrm{~mm}$ step length, and 2000 steps per sample. For each tract, seed masks, way-points, termination and exclusion masks were defined on the MNI152 T1 $1 \mathrm{~mm}$ template. Masks were normalized to each subjects' diffusion space using FLIRT (Jenkinson and Smith, 2001), applying the affine parameters obtained by coregistering the first b0 volume to the MNI152 T1 $1 \mathrm{~mm}$ template. The resulting tracts were thresholded at a normalized probability level and then visually inspected to confirm successful tracing in each individual subject.

In the CAMH data, whole-brain tractography was performed with a deterministic (streamline) approach (Runge-Kutta order 2 tractography with a fixed step size of $0.5 \mathrm{~mm}$ ). Detailed descriptions of this tractography approach and our clustering segmentation algorithm have been published (O'Donnell et al., 2006; Voineskos et al., 2009) and are summarized here. A brain "mask" was generated and points were seeded throughout each voxel of the brain. Threshold parameters for tractography were based on the linear anisotropy measure $C_{\mathrm{L}}$, where $C_{\mathrm{L}}=\left(\lambda_{1}-\right.$ $\left.\lambda_{2}\right) / \lambda_{1}$ and, $\lambda_{1}$ and $\lambda_{2}$ are the two largest eigenvalues of the diffusion tensor sorted in descending order. The parameters chosen for this study were as follows: T-seed, $C_{\mathrm{L}}=0.3$; T-stop, 0.15 ; and T-length, $20 \mathrm{~mm}$. 
Table 1. Sample characteristics by FADS haplotype ${ }^{a}$

\begin{tabular}{|c|c|c|c|c|}
\hline & Age (years) & $\begin{array}{l}\text { Sex } \\
\text { (male/female) }\end{array}$ & $\begin{array}{l}\text { Handedness } \\
\text { (right/left) }\end{array}$ & $\begin{array}{l}\mathrm{IQ}^{b} \\
(\text { mean } \pm S D)\end{array}$ \\
\hline $\begin{array}{l}\text { Major allele } \\
\quad \text { carriers } \\
\quad(n=177)\end{array}$ & $37.9 \pm 18.5(8.8-86.0)$ & $98 / 79$ & $158 / 19$ & $112 \pm 11$ \\
\hline $\begin{array}{l}\text { Minor allele } \\
\text { homozgotes } \\
(n=30)\end{array}$ & $45.1 \pm 22.0(9.9-81.0)$ & $11 / 19$ & $26 / 4$ & $113 \pm 12$ \\
\hline
\end{tabular}

${ }^{a}$ Age and IQ are mean \pm SD. Data were collected at two study sites. Haplotype status was determined with the rs 174583 SNP within the FADS2 gene, which tags a haplotype spanning the FADS1 gene and first part of the FADS2 gene (Ameur et al., 2012).

${ }^{b}$ Estimated using the Wide Range Achievement Test 3 (Reading subtest; Wilkinson, 1993); data missing for 13 major allele carriers and 2 minor allele homozygotes.

Tractography and creation of white matter fiber tracts were performed using 3D Slicer (www.slicer.org) and MATLAB 7.0 (www.mathworks. com). A pairwise fiber trajectory similarity was quantified and the directed distances between fibers $\mathrm{A}$ and $\mathrm{B}$ were converted to a symmetric pairwise fiber distance. A spectral embedding of fibers was then created based on the eigenvectors of the fiber affinity matrix, and shape similarity information for each fiber was calculated using a $k$-way normalized cuts clustering algorithm (O'Donnell et al., 2006). Once the whole-brain cluster model was produced, clusters were selected that corresponded to the above listed fiber tracts. As reported previously, excellent spatial and quantitative reliability using this clustering method has been demonstrated (Voineskos et al., 2009).

After the tractography procedures, mean fractional anisotropy (FA), a putative measure of axonal fiber coherence and myelination (Sakuma et al., 1991; Beaulieu, 2002), was extracted from each tract. FA values of bilateral tracts were collapsed across hemispheres because prior analyses indicated no significant WM tract FA differences between the left and right hemispheres across the age span (Peters et al., 2014).

Tract-based spatial statistics. To provide validation of the tractography analysis, DTI data from both study sites were also analyzed with one tract-based spatial statistics procedure (TBSS; Smith et al., 2006), following the ENIGMA protocol (http://enigma.ini.usc.edu/ongoing/dtiworking-group) (Jahanshad et al., 2013). First, nonbrain tissue of all subjects' FA maps was removed using FSL's Brain Extraction Tool. FA images then underwent nonlinear registration to the ENIGMA FA template (Jahanshad et al., 2013), which is based on the Johns Hopkins University DTI atlas in ICBM space (ICBM-DTI-81 WM labels atlas) (Mori et al., 2008). Next, each subject's FA image was "projected" onto the WM "skeleton" of the ENIGMA FA template, which represents the centers of all WM tracts common to the group, to create an FA skeleton in the same space for each individual. Then, we extracted for each subject mean FA of the complete WM skeleton and of five WM ROIs, which approximately corresponded to six of the seven above listed WM tracts, predefined on the ENIGMA template in ICBM space according to the Johns Hopkins University WM parcellation atlas (Mori et al., 2008; Jahanshad et al., 2013): splenium and genu of CC, sagittal stratum (SS, which contains a major part of the posterior temporal and occipital fibers of the ILF and IFOF), SLF, and cingulum. The bilateral uncinate fasciculus is not provided in the ENIGMA output. The ENIGMA output provides mean FA of eight additional ROIs, which we included for exploratory analyses: body of CC, corticospinal tract (CST), corona radiata (CR, containing thalamic and long corticofugal projection fibers), posterior thalamic radiation (PTR), internal capsule (IC, containing thalamic and long corticofugal projection fibers), external capsule (EC, containing association fibers, including IFOF and SLF, and commissural fibers), superior fronto-occipital fasciculus (SFOF), and fornix. Mean FA values of bilateral ROIs were averaged, weighted by the number of voxels in each hemisphere.

Genotyping. We determined haplotype status of the FADS haplotype associated with periperhal LC-PUFA concentrations (Ameur et al., 2012) with the single nucleotide polymorphism (SNP) rs174583 within the FADS2 gene. In the original report of Ameur et al. (2012), as well as in our dataset, this SNP is in nearly perfect linkage disequilibrium $\left(\mathrm{D}^{\prime}=1, r^{2}>\right.$
Table 2. Age-adjusted residuals of WM tract FA by FADS haplotype: tractography results $^{a}$

\begin{tabular}{|c|c|c|c|c|c|c|c|}
\hline WM tracts & Haplotype $^{b}$ & $n$ & Mean residual & SD & $t$ & df & $p$ \\
\hline \multirow[t]{2}{*}{ Splenium of CC } & 1 & 176 & 0.04799 & 0.99835 & \multirow[t]{2}{*}{1.675} & \multirow[t]{2}{*}{204} & \multirow[t]{2}{*}{0.096} \\
\hline & 0 & 30 & -0.28396 & 1.03478 & & & \\
\hline \multirow[t]{2}{*}{ Genu of CC } & 1 & 177 & 0.05482 & 0.99725 & \multirow[t]{2}{*}{1.954} & \multirow[t]{2}{*}{205} & \multirow[t]{2}{*}{0.052} \\
\hline & 0 & 30 & -0.33132 & 1.02329 & & & \\
\hline \multirow[t]{2}{*}{ ILF } & 1 & 175 & 0.03348 & 1.01211 & \multirow[t]{2}{*}{1.164} & \multirow[t]{2}{*}{203} & \multirow[t]{2}{*}{0.246} \\
\hline & 0 & 30 & -0.19800 & 0.96925 & & & \\
\hline \multirow[t]{2}{*}{ IFOF } & 1 & 176 & 0.01950 & 0.99339 & \multirow[t]{2}{*}{0.699} & \multirow[t]{2}{*}{204} & \multirow[t]{2}{*}{0.486} \\
\hline & 0 & 30 & -0.11956 & 1.09177 & & & \\
\hline \multirow[t]{2}{*}{ SLF } & 1 & 175 & 0.02928 & 1.03049 & \multirow[t]{2}{*}{1.005} & \multirow[t]{2}{*}{203} & \multirow[t]{2}{*}{0.316} \\
\hline & 0 & 30 & -0.17067 & 0.85102 & & & \\
\hline \multirow[t]{2}{*}{ Cingulum } & 1 & 177 & 0.06960 & 0.99189 & \multirow[t]{2}{*}{2.453} & \multirow[t]{2}{*}{205} & \multirow[t]{2}{*}{$0.015^{*}$} \\
\hline & 0 & 30 & -0.41219 & 1.01349 & & & \\
\hline \multirow[t]{2}{*}{ Uncinate } & 1 & 175 & 0.01798 & 1.001965 & \multirow[t]{2}{*}{0.600} & \multirow[t]{2}{*}{203} & \multirow[t]{2}{*}{0.549} \\
\hline & 0 & 30 & -0.10176 & 1.05597 & & & \\
\hline \multirow{2}{*}{$\begin{array}{l}\text { WM tract factor } \\
\text { score }^{c}\end{array}$} & 1 & 175 & 0.05558 & 1.01006 & \multirow[t]{2}{*}{1.922} & \multirow[t]{2}{*}{203} & \multirow[t]{2}{*}{0.056} \\
\hline & 0 & 30 & -0.32444 & 0.94074 & & & \\
\hline
\end{tabular}

${ }^{a}$ Residuals are FA values adjusted for age using a Poisson model $\left(c+a \times\right.$ Age $\times \exp \left(-b \times\right.$ Age $\left.\left.^{2}\right)\right)$. Haplotype status was determined with the rs174583 SNP within the FADS2 gene, which tags a haplotype spanning the FADS gene and first part of the FADS2 gene; the minor allele of this haplotype is associated with lower plasma levels of long-chain omega- 6 and omega-3 fatty acids (Ameur et al., 2012). Data were collected at two study sites.

${ }^{b} 1=$ major allele carriers; $0=$ minor allele homozygotes.

'Because the tract-averaged FA values of the studied WM tracts were all significantly positively correlated, a general principal component (factor score) was extracted from the individual WM tracts, which was positively loaded by all tracts and explained $>50 \%$ of the variance shared among all tracts.

${ }^{*} p$ value for the cingulum was not significant after correction for multiple comparisons of seven individual WM tracts using Holm's procedure ( $\left.p_{\text {corrected }}=0.105\right)($ Holm, 1979).

Table 3. Age-adjusted residuals of cerebral WM FA by FADS haplotype: TBSS results ${ }^{a}$

\begin{tabular}{llrrlrll}
\hline WM tracts & Haplotype $^{b}$ & $n$ & Mean residual & SD & $t$ & df & $p$ \\
\hline Splenium of CC & 1 & 175 & 0.043351 & 0.98418 & 1.539 & 203 & 0.125 \\
\multirow{4}{*}{ Genu of CC } & 0 & 30 & -0.26204 & 1.11510 & & & \\
& 1 & 174 & 0.07303 & 0.99619 & 2.549 & 202 & $0.012^{*}$ \\
SS & 0 & 30 & -0.42815 & 0.98486 & & & \\
& 1 & 176 & -0.00663 & 1.00384 & -0.202 & 204 & 0.840 \\
SLF & 0 & 30 & 0.03371 & 1.04536 & & & \\
\multirow{2}{*}{ Cingulum } & 1 & 176 & 0.03420 & 1.00218 & 1.202 & 204 & 0.231 \\
& 0 & 30 & -0.20436 & 1.02275 & & & \\
TBSS WM skeleton & 1 & 176 & 0.07494 & 1.00420 & 2.631 & 204 & $0.009^{*}$ \\
& 0 & 30 & -0.44136 & 0.92675 & & & \\
& 0 & 175 & 0.05552 & 1.00446 & 1.940 & 203 & 0.054 \\
& 1 & 30 & -0.32795 & 0.97522 & & & \\
\hline
\end{tabular}

${ }^{a}$ Residuals are FA values adjusted for age using a Poisson model $\left(c+a \times\right.$ Age $\times \exp \left(-b \times\right.$ Age $\left.\left.^{2}\right)\right)$. Haplotype status was determined with the rs174583 SNP within the FADS2 gene, which tags a haplotype spanning the FADS gene and first part of the FADS2 gene; the minor allele of this haplotype is associated with lower plasma levels of long-chain omega- 6 and omega-3 fatty acids (Ameur et al., 2012). Data were collected at two study sites.

${ }^{b} 1=$ major allele carriers; $0=$ minor allele homozygotes.

${ }^{*} p$ values for the genu of $C($ and cingulum were significant after correction for multiple comparisons of five WM ROI using Holm's procedure ( $p_{\text {corrected }}=0.048$ and 0.045 , respectively) (Holm, 1979).

0.9) with all remaining SNPs in the haplotype, and thus serves as an efficient haplotype tag. Genotyping of rs174583 in $\mathrm{ZHH}$ subjects was performed as part of a larger study of $\sim 700 \mathrm{~K}$ genome-wide SNPs using Illumina Omni Express arrays processed according to manufacturer's specifications (Illumina). This SNP met strict quality control specifications (call rate $=100 \%$, minor allele frequency $=31.5 \%$, Hardy-Weinberg Equilibrium $p=0.82$ ). Samples were filtered based on genotype quality control filtration (sample call rate $<97 \%$, gender mismatch). Principal component analysis was performed with 98,629 LD pruned $\left(r^{2}>0.2\right)$ genome-wide SNPs to confirm white ancestry identified by self-report of the subjects based on the ethnicity of parents and grandparents $(n=107)$. Genotyping of rs174583 in CAMH subjects was performed using a standard ABI (Applied Biosystems) 5' nuclease TaqMan assay-on-demand protocol in a total volume of $10 \mu$ l. Postamplification products were analyzed on the ABI 7500 Sequence Detection System and genotype calls were performed manually. Results were verified indepen- 
Table 4. Age $\times$ genotype interaction results for cerebral WM tract FA: tractography and TBSS results ${ }^{a}$

\begin{tabular}{|c|c|c|c|c|c|c|c|c|c|c|}
\hline \multirow[b]{3}{*}{ WM tract } & \multicolumn{5}{|c|}{ Tractography } & \multicolumn{5}{|c|}{ TBSS } \\
\hline & \multirow[b]{2}{*}{$\mathrm{df}$} & \multicolumn{2}{|l|}{$a$-term } & \multicolumn{2}{|l|}{$b$-term } & \multirow[b]{2}{*}{ df } & \multicolumn{2}{|c|}{$a$-term } & \multicolumn{2}{|l|}{$b$-term } \\
\hline & & $t$ & $p^{*}$ & $t$ & $p^{*}$ & & $t$ & $p^{*}$ & $t$ & $p^{*}$ \\
\hline Global WM ${ }^{b}$ & 203 & 4.2 & $<0.0001$ & 19939 & $<0.0001$ & 203 & 5.6 & $<0.0001$ & 50470 & $<0.0001$ \\
\hline Splenium CC & 204 & 0.5 & 0.3259 & 55 & $<0.0001$ & 203 & 3.6 & 0.0002 & 24785 & $<0.0001$ \\
\hline Genu CC & 205 & 4.8 & $<0.0001$ & 30062 & $<0.0001$ & 202 & 6.6 & $<0.0001$ & 31183 & $<0.0001$ \\
\hline ILF & 203 & 3.6 & 0.0002 & 3287 & $<0.0001$ & - & - & - & - & - \\
\hline SS & - & - & - & - & - & 204 & 4.3 & $<0.0001$ & 32044 & $<0.0001$ \\
\hline IFOF & 204 & 4.0 & $<0.0001$ & 23833 & $<0.0001$ & - & - & - & - & - \\
\hline SLF & 203 & 2.9 & 0.0020 & 8226 & $<0.0001$ & 204 & 6.3 & $<0.0001$ & 134 & $<0.0001$ \\
\hline Uncinate & 203 & 2.4 & 0.0079 & 11480 & $<0.0001$ & - & - & - & - & - \\
\hline Cingulum & 205 & $<0.1$ & 0.4908 & 2853 & $<0.0001$ & 204 & 0.2 & 0.4285 & 8283 & $<0.0001$ \\
\hline
\end{tabular}

${ }^{a}$ Haplotype status was determined with the rs174583 SNP within the FADS2 gene, which tags a haplotype spanning the FADS1 gene and first part of the FADS2 gene; the minor allele of this haplotype is associated with lower plasma levels of long-chain omega- 6 and omega- 3 fatty acids (Ameur et al., 2012). Age $\times$ genotype interactions were examined using a Poisson model $\left(c+a \times\right.$ Age $\times$ exp $\left(-b \times\right.$ Age $\left.{ }^{2}\right)$ ). Data were collected at two study sites.

${ }^{b}$ The global WM measure for tractography data comprised a general principal component (factor score) extracted from the seven individual WM tracts, which was positively loaded by all tracts and explained $>50 \%$ of the variance shared among all tracts. For TBSS data, the individual ROIs did not all significantly correlate among each other so that one principal component could not be extracted; therefore, mean FA of the whole TBSS WM skeleton, which represents the centers of all cerebral WM tracts, was used as a global measure.

*Significant $p$ values $(p<0.05)$ remained significant after correction for multiple comparisons using Holm's procedure $\left(p_{\text {corrected }}(\right.$ all $\left.)<0.05\right)($ Holm, 1979).

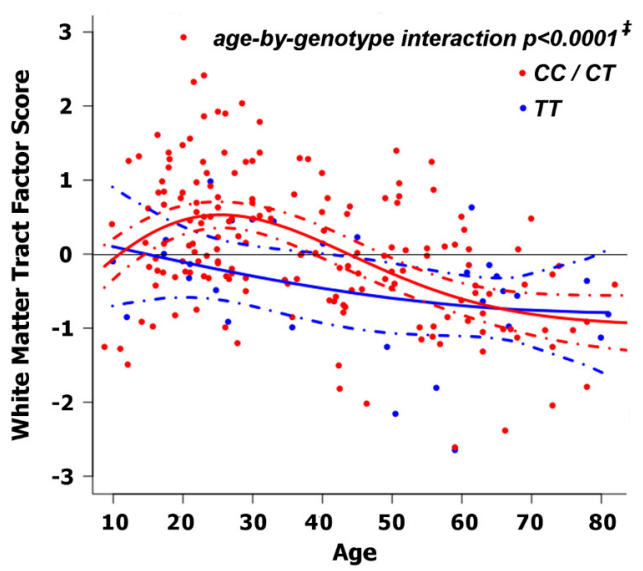

Figure 1. Associations between age and WM tract FA by FADS haplotype in healthy individuals: tractography results. Blue represents minor allele (T) homozygotes $(n=30)$; red represents major allele ( $C$ ) carriers ( $n=175$ ). A general principal component (factor score), gFA, was extracted from seven studied white matters, which was positively loaded by all tracts and explained $>50 \%$ of the variance shared among all tracts. Haplotype status was determined with the rs 174583 SNP within the FADS2 gene, which tags a haplotype spanning the FADS1 gene and first part of the FADS2 gene; the minor allele of this haplotype is associated with lower plasma levels of long-chain $\omega-6$ and $\omega$-3 fatty acids (Ameur et al., 2012). $¥$ Age $\times$ genotype interactions were examined using a Poisson model $\left(c+a \times \operatorname{Age} \times \exp \left(-b \times\right.\right.$ Age $\left.\left.^{2}\right)\right)$; the interaction was significant at $p<0.0001$ for the " $a$ " term and $p<0.0001$ for the " $b$ " term. Data were collected at two study sites.

dently by laboratory personnel blind to demographic and phenotypic information. Genotyping accuracy was assessed by repeating $10 \%$ of the sample. Self-report of the subjects was used to determine ethnicity based on the ethnicity of parents and grandparents. Only subjects identified as white were included for further analysis $(n=100)$.

Statistical analysis. Statistical analyses were conducted in the Statistical Package for the Social Sciences, version 11.5.1 (IBM; www.spss.com), and the nls2 package in "R", version 2.15.1 (www.r-project.org).

Subjects were grouped according to whether they were major allele (C) carriers or minor allele (T) homozygotes at the rs174583 SNP. The recessive model was chosen for analysis in accordance with the study of Ameur et al. (2012), in which minor allele homozygotes were shown to have lower FADS gene expression and lower LC-PUFA levels.

We compared age, sex, handedness, and IQ, as potential confounders, between the haplotype groups using independent sample $t$ tests and Pearson's $\chi^{2}$ tests. In addition, we compared diastolic and systolic blood pressures, as a proxy for atherosclerosis/vascular disease, between genotype groups in subjects $>54$ years of age, considering the inverse rela-

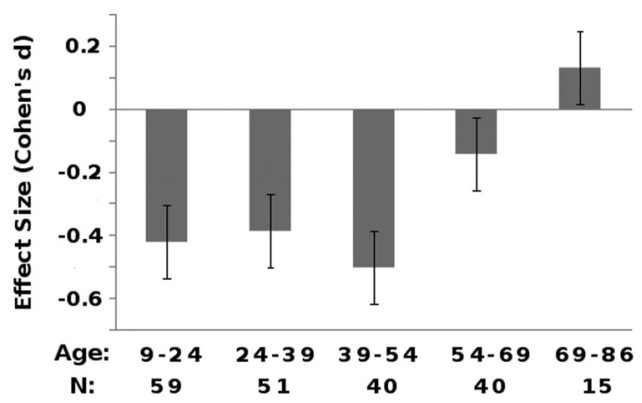

Figure 2. Differences in WM tract FA between FADS haplotypes, by age group. Negative effect sizes indicate lower FA values in minor allele (T) homozygotes, compared with major allele (C) carriers. Number of C-carriers in each age group: $n=53, n=44, n=36, n=30$, and $n=12$, respectively. Number of TT homozygotes in each age group: $n=6, n=7, n=4, n=$ 10 , and $n=3$, respectively. Error bars indicate SEM. A general principal component (factor score), $\mathrm{gFA}$, was extracted from seven studied white matter tracts, which was positively loaded by all tracts and explained $>50 \%$ of the variance shared among all tracts. Haplotype status was determined with the rs 174583 SNP within the FADS2 gene, which tags a haplotype spanning the FADS1 gene and first part of the FADS2 gene; the minor allele of this haplotype is associated with lower plasma levels of long-chain $\omega-6$ and $\omega$-3 fatty acids (Ameur et al., 2012). Data were collected at two study sites.

tionship between LC-PUFA levels and atherosclerosis/cerebrovascular disease (Kim et al., 2012). Last, we assessed study site as a potential confounder by comparing age and frequency of minor allele homozygosity between study sites using independent sample $t$ test and Pearson's $\chi^{2}$ test, respectively.

Because the tract-averaged FA values of the seven studied WM tracts (splenium and genu of CC, ILF, IFOF, SLF, cingulum, and uncinate) were all significantly positively correlated $(\mathrm{r}$ (range) $=0.239-0.746$, $p($ all $) \leq 0.025)$, and we did not have an a priori hypothesis of a tractspecific effect of FADS haplotype, principal component analysis was performed to extract a general factor, gFA, for each study site (similar to Lopez et al., 2012). Because factor scores are normally distributed $\sim 0$ with an SD of 1, this allowed combining gFA values between the two study sites. For TBSS data, the individual WM ROIs were not all significantly correlated ( $p>0.05$ for $10.5 \%$ of all correlations among the two study sites), so that one principal component could not be extracted; therefore, average FA of the complete TBSS WM skeleton was used as a global measure. TBSS WM skeleton FA, TBSS WM ROI FA as well as WM tract FA values were standardized to $z$-scores for each study site separately before combining them among sites. To ensure there were no significant differences in distribution of the factor scores or $z$-scores between sites, these were compared using the Kolmogorov-Smirnov (KS) and Anderson-Darling (AD) tests. 


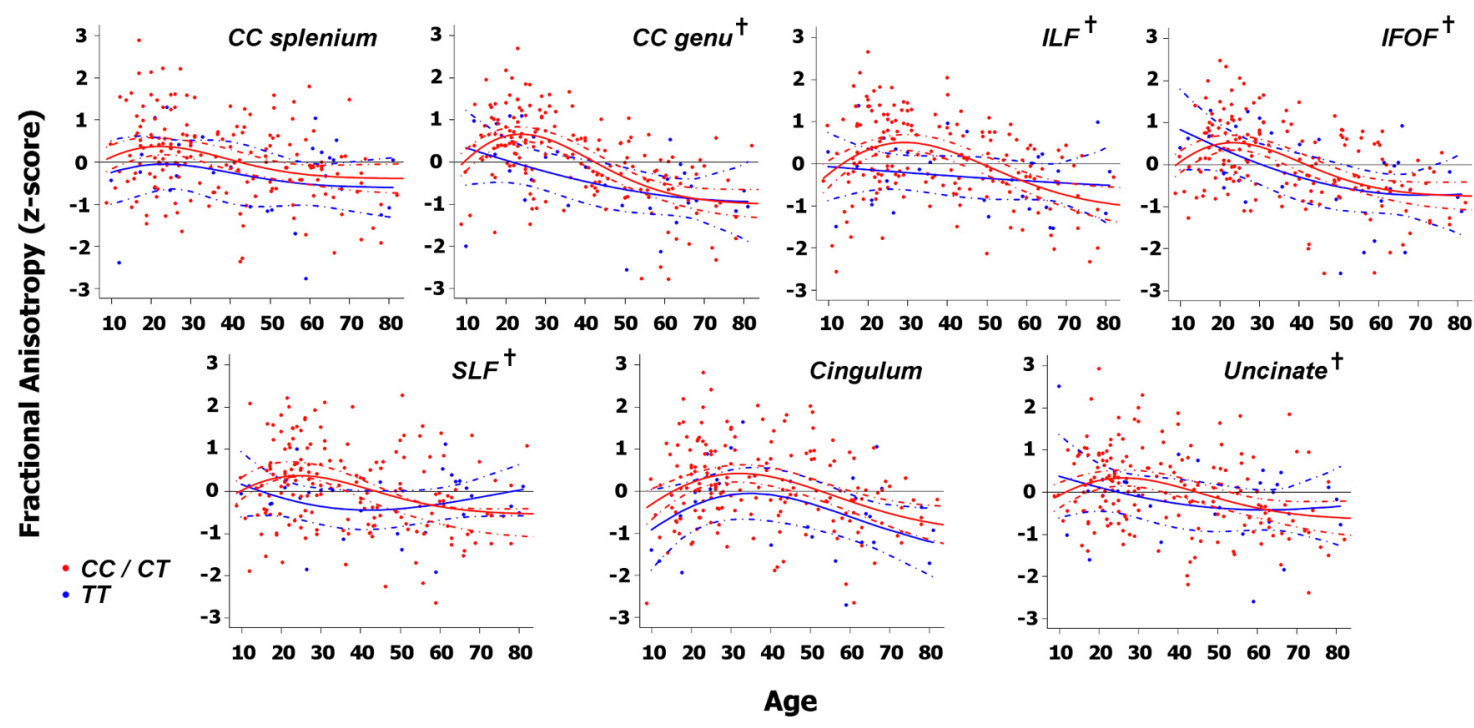

Figure 3. Associations between age and WM tract FA by FADS haplotype in healthy individuals: tractography results. Blue represents minor allele (T) homozygotes $(n=30)$; red represents major allele $(C)$ carriers ( $n$ range $=175-177$ ). Haplotype status was determined with the rs174583 SNP within the FADS2 gene, which tags a haplotype spanning the FADS1 gene and first part of the FADS2 gene; the minor allele of this haplotype is associated with lower plasma levels of long-chain $\omega-6$ and $\omega$-3 fatty acids (Ameur et al., 2012). †Age $\times$ genotype interactions in a Poisson model ( $c+$ $a \times$ Age $\times \exp \left(-b \times\right.$ Age $\left.\left.^{2}\right)\right)$ were significant for the genu of CC, ILF, IFOF, and SLF, which survived Holm's correction $(H o l m, 1979)$ for multiple comparisons ( $p_{\text {corrected }}($ all $)<0.05$ for the " $a$ " and " $b$ " terms in the Poisson model). Data were collected at two study sites.

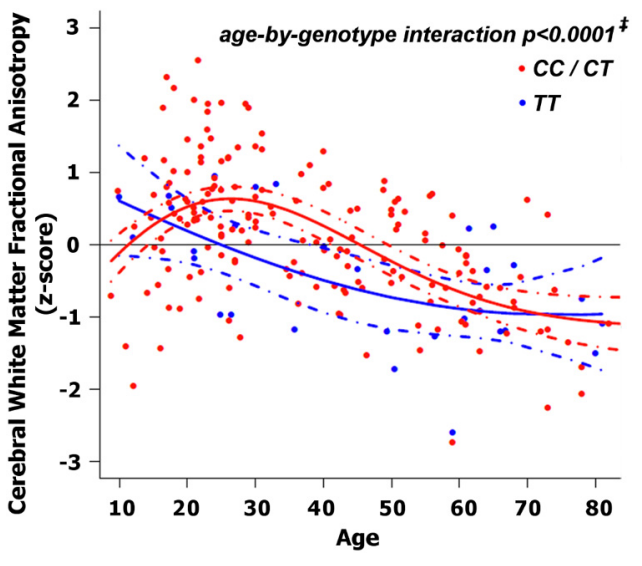

Figure 4. Associations between age and cerebral WM FA by FADS haplotype in healthy individuals: TBSS results. Blue represents minor allele (T) homozygotes $(n=30)$; red represents major allele $(C)$ carriers $(n=176)$. Mean cerebral white matter FA was obtained from the centers of all cerebral white matter tracts using TBSS (Smith et al., 2006) following the ENIGMA protocol (Jahanshad et al., 2013). Haplotype status was determined with the rs 174583 SNP within the FADS2 gene, which tags a haplotype spanning the FADS1 gene and first part of the FADS2 gene; the minor allele of this haplotype is associated with lower plasma levels of longchain $\omega-6$ and $\omega-3$ fatty acids (Ameur et al., 2012). $¥$ Age $\times$ genotype interactions were examined using a Poisson model $\left(c+a \times\right.$ Age $\times \exp \left(-b \times\right.$ Age $\left.\left.^{2}\right)\right)$; the interaction was significant at $p<0.0001$ for the " $a$ " term and $p<0.0001$ for the " $b$ " term. Data were collected at two study sites.

We first assessed the main effect of genotype on FA, independent of the effect of age. For this purpose, we calculated the age-adjusted residuals of gFA and FA $z$-scores using a nonlinear Poisson model $(c+a \times$ Age $\times$ $\left.\exp \left(-b \times \mathrm{Age}^{2}\right)\right)$ (Lebel et al., 2012; Peters et al., 2014) and compared them between the genotype groups using independent sample $t$ tests.

To examine the effect of genotype on age-related FA differences across the life span, age $\times$ genotype interactions (minor allele homozygotes vs major allele carriers) were assessed. The Poisson model ( $c+a \times$ Age $\times$ $\left.\exp \left(-b \times \mathrm{Age}^{2}\right)\right)$ was used to assess these interactions, considering the well-established nonlinear age-FA associations across the life span (Westlye et al., 2010; Peters et al., 2014). Differences between the CC/CT curves and TT curves were assessed by comparing the differences in the
" $a$ " coefficient and " $b$ " coefficient in the Poisson model separately. Both " $a$ " and " $b$ " contribute to the shape ("slope" and "curvature") of the curve, whereas " $c$ " is the intercept. Differences in the " $a$ " coefficient between CC/CT and TT groups were divided by the SE of the difference to obtain a $t$-statistic. $p$ values were obtained by calculating the two-sided tail area of the corresponding null $t$-distribution. $p$ values for differences in the " $b$ " coefficient were obtained similarly.

Correction for multiple comparisons was performed using Holm's method (Holm, 1979). The statistical threshold was set at $p_{\text {corrected }}<$ 0.05 .

\section{Results}

Subject grouping according to rs174583 genotype yielded 177 major allele (C) carriers (88 CC homozygotes, $89 \mathrm{C} / \mathrm{T}$ heterozygotes) and 30 minor allele (T) homozygotes. There were no significant differences between minor allele homozygotes and major allele carriers in age $(t=1.9, \mathrm{df}=205, p=0.055)$, $\operatorname{sex}\left(\chi^{2}=3.6\right.$, $\mathrm{df}=1, p=0.058$ ), handedness (Fisher's exact test, $p=0.752$ ), or IQ $(t=-0.5, \mathrm{df}=190, p=0.621)$ (Table 1$)$. In older subjects (>54 years), there were no significant differences in systolic or diastolic blood pressures between minor allele homozygotes and major allele carriers (systolic: $t=-0.2, \mathrm{df}=34, p=0.807$; diastolic: $t=0.5, \mathrm{df}=34, p=0.623 ; n=36$, data missing for 15 major allele carriers and 4 minor allele homozygotes). There was no significant difference between study sites in the frequency of minor allele homozygosity $\left(\chi^{2}<0.1\right.$, $\left.\mathrm{df}=1, p=0.841\right)$, but subjects from CAMH were on average older than subjects from $\mathrm{ZHH}$ (mean ages $46.5 \pm 19.5$ and $31.8 \pm 16.0$ years, respectively; $t=5.9, \mathrm{df}=192, p<0.0001)$. Therefore, analyses of the main effects and of the age $\times$ genotype interactions were also conducted while adjusting for study site, using analysis of covariance and using the formula $c+a \times$ Age $\times \exp \left(-b \times\right.$ Age $\left.^{2}\right)+d \times$ Site, respectively.

Principal component analysis of the tract-averaged FA values was performed in 206 of 207 included subjects because in one subject the SLF could not be traced successfully. The gFA of each site was positively loaded by all tracts and explained $>50 \%$ of the variance shared among all tracts. One subject's gFA value was an extreme outlier ( $>3$ SDs from the mean), and was therefore re- 
moved from further analysis. This yielded a total sample of 205 subjects for the gFA analysis. The FA $z$-scores of the individual WM tracts showed extreme outliers for the splenium of CC $(n=1), \operatorname{ILF}(n=2)$, IFOF $(n=1), \operatorname{SLF}(n=1)$, and uncinate $(n=2)$. This yielded 207 subjects in total for analysis of the genu of CC and cingulum, 206 subjects for analysis of the splenium of CC and IFOF, and 205 subjects for analysis of the ILF, SLF, and uncinate. TBSS was performed in 206 of 207 included subjects because in one subject a frontal part of the FA map was missing so that not all ENIGMA ROIs could be extracted. The TBSS WM skeleton $z$-scores showed one extreme outlier, yielding 205 subjects in total for further analysis. TBSS WM ROI $z$-scores showed extreme outliers for the splenium of CC $(n=1)$, genu of CC $(n=2)$, body of CC $(n=1)$, IC $(n=1)$, SFOF $(n=2)$, and fornix $(n=4)$. This yielded 206 subjects in total for analysis of the SS, SLF, cingulum, CST, CR, PTR, and EC; 205 subjects for analysis of the splenium of CC, body of CC, and IC; 204 subjects for analysis of the genu of CC and SFOF; and 202 subjects for analysis of the fornix. No significant differences were observed between study sites in the distributions of gFA (KS test: $\mathrm{Z}=0.7, p=0.650$; $\mathrm{AD}$ test: $t=-0.9, p=0.604$ ), individual WM tract $z$-scores (KS test: $\mathrm{Z}($ all $)<=0.9, p($ all $) \geq 0.377$; AD test: $t($ all $)<=0.3, p($ all $) \geq$ 0.419 ), TBSS WM skeleton $z$-scores (KS test: $Z=0.1, p=0.993$; AD test: $t=-0.8, p=0.583$ ), or TBSS WM ROI $z$-scores (KS test: $\mathrm{Z}($ all $)<=0.9, p($ all $) \geq 0.376$; AD test: $t$ (all $)<=0.3, p($ all $) \geq$ $0.267)$, except for the fornix (KS test: $Z=1.4, p=0.043$ ( $p_{\text {corrected }}=$ $0.559)$; AD test: $t=3.9, p=0.008\left(p_{\text {corrected }}=0.104\right)$.

Analysis of the main effects of genotype on age-adjusted gFA or FA $z$-scores (after excluding previously removed outliers) showed that FA of the cingulum and of the genu of CC was lower in minor allele homozygotes, compared with major allele carriers, which was significant in the TBSS analysis, after Holm's correction for five ROIs (Tables 2 and 3). This effect was also observed, yet to a lesser extent, for gFA, TBSS WM skeleton $z$-scores, individual WM tract $z$-scores, and TBSS WM ROI $z$-scores (except for the SS) (Tables 2 and 3). All of the eight additional TBSS ROIs (body of CC, CST, CR, PTR, IC, EC, SFOF, and fornix) showed lower FA $z$-scores in minor allele homozygotes, compared with major allele carriers, which did not reach statistical significance after Holm's correction ( $p_{\text {corrected }}($ all $)>0.05$ ). Adjusting for study site as a covariate did not alter the results, that is, significant results remained significant and nonsignificant results remained nonsignificant.

The age $\times$ genotype interaction on gFA was significant for the " $a$ " and " $b$ " terms in the Poisson model $(c+a \times$ Age $\times$ $\exp \left(-b \times \mathrm{Age}^{2}\right)$ ), such that minor allele homozygotes did not display normal age-related gFA differences from childhood to old age, which were observed in major allele carriers (Table 4). Specifically, individuals homozygous for the minor allele failed to show higher gFA values in early adulthood compared with childhood and older age ranges but rather displayed little gFA differences between childhood and old age (Fig. 1). The age $\times$ genotype interaction remained significant after adjusting for study site ( $\mathrm{df}=203, t=5.0, p<0.0001$ for the " $a$ " term and $t=$ 25824, $p<0.0001$ for the " $b$ " term in the Poisson model). To further delineate this effect, we calculated the effect sizes (Cohen's $d$ ) of the between-genotype gFA differences per age groups of 15 years. The effect sizes indicated substantially lower gFA values in minor allele homozygotes, compared with major allele carriers, in childhood and early and middle adulthood, but little between-genotype gFA differences in late adulthood and old age (Fig. 2), consistent with the age $\times$ genotype interaction.

The age $\times$ genotype interactions on the individual WM tract $z$-scores were significant for the genu of CC, ILF, IFOF, SLF, and uncinate, after Holm's correction for seven WM tracts (Table 4). For these significant tracts, minor allele homozygotes did not display normal age-related FA differences from childhood to old age, which were observed in major allele carriers (Fig. 3). The age $\times$ genotype interaction was not significant for the splenium of CC or cingulum (Fig. 3; Table 4). Notably, the cingulum showed normal age-related FA differences in both genotype groups (Fig. 3), but individuals homozygous for the minor allele displayed lower FA values than major allele carriers across the life span. Adjusting for study site as a covariate did not alter the results.

The age $\times$ genotype interaction on the TBSS WM skeleton $z$-scores was significant for the " $a$ " and " $b$ " terms in the Poisson model (Table 4), such that minor allele homozygotes did not display normal age-related FA differences from childhood to old age, which were observed in major allele carriers (Fig. 4). Specifically, individuals homozygous for the minor allele failed to show higher FA values in early adulthood compared with childhood and older age ranges but rather displayed FA values highest in childhood and lowest in old age (Fig. 4). The age $\times$ genotype interaction remained significant after adjusting for study site $(\mathrm{df}=203, t=6.4, p<0.0001$ for the " $a$ " term and $t=57364, p<$ 0.0001 for the " $b$ " term in the Poisson model).

The age $\times$ genotype interactions on the $z$-scores of the TBSS WM ROIs that approximately corresponded to the individual 

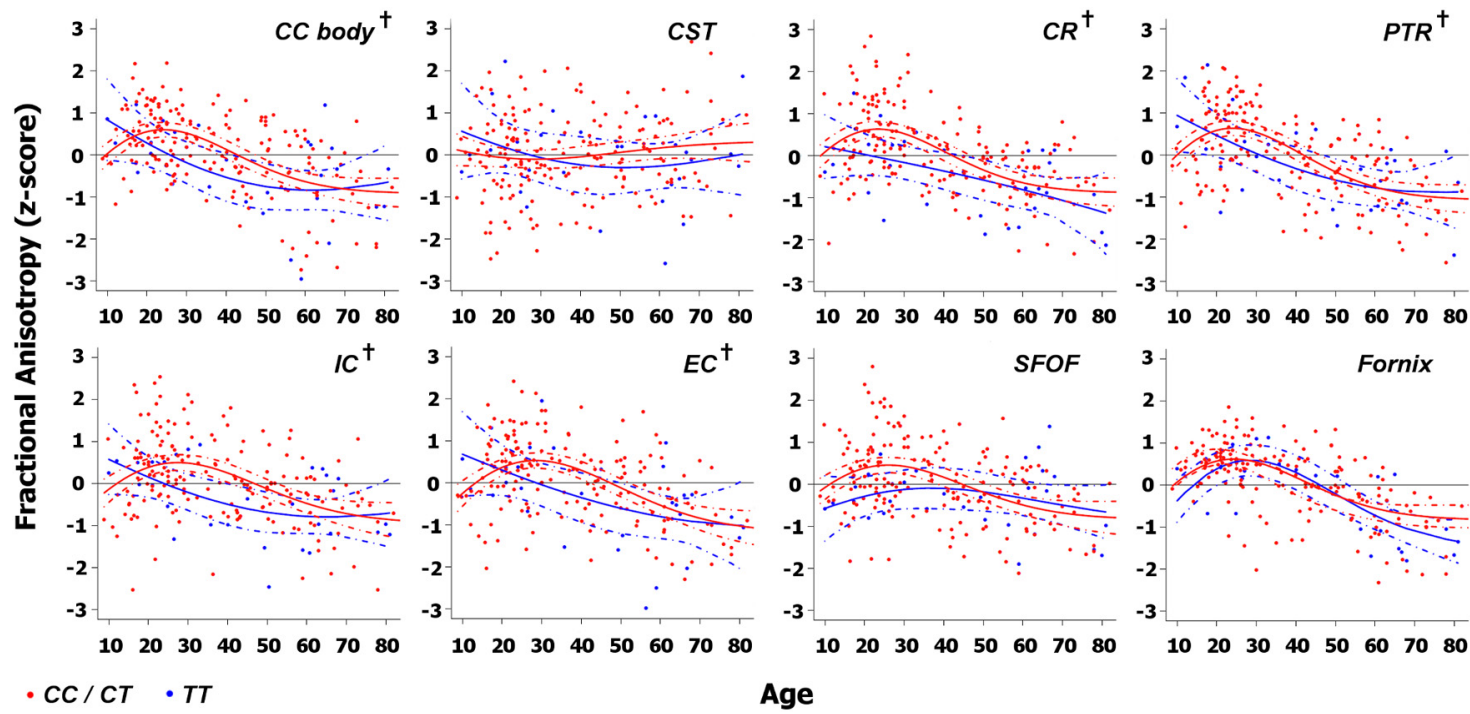

Figure 6. Associations between age and cerebral WM FA by FADS haplotype in healthy individuals: additional TBSS results. Blue represents minor allele (T) homozygotes ( $n=30$ ); red represents major allele $(C)$ carriers ( $n$ range $=174-176$ ). Haplotype status was determined with the rs 174583 SNP within the FADS2 gene, which tags a haplotype spanning the FADS1 gene and first part of the FADS2 gene; the minor allele of this haplotype is associated with lower plasma levels of long-chain $\omega$ - 6 and $\omega$-3 fatty acids (Ameur et al., 2012). †Age $\times$ genotype interactions in a Poisson model $\left(c+a \times\right.$ Age $\times \exp \left(-b \times\right.$ Age $\left.\left.^{2}\right)\right)$ were significant for the body of CC, CR, PTR, IC, and EC, which survived Holm's correction (Holm, 1979) for multiple comparisons ( $p_{\text {corrected }}($ all) $<0.05$ for the " $a$ " and " $b$ " terms in the Poisson model). Data were collected at two study sites.

WM tracts, were significant for the genu and splenium of CC, SS, and SLF, after Holm's correction for five WM ROIs (Table 4). For these significant ROIs, minor allele homozygotes did not display normal age-related FA differences from childhood to old age, which were observed in major allele carriers (Fig. 5). The cingulum showed normal age-related FA differences in both genotype groups, but individuals homozygous for the minor allele displayed lower FA values than major allele carriers across the life span (Fig. 5). Adjusting for study site as a covariate did not alter the results.

The age $\times$ genotype interactions on the eight additional TBSS WM ROI $z$-scores were significant for the body of CC, CR, PTR, IC, and EC $\left(t(\right.$ all $) \geq 4.0, p($ all $)<0.0001\left(p_{\text {corrected }}(\right.$ all $\left.)<0.05\right)$ for the " $a$ " terms and $t$ (all) $\geq 23200, p$ (all) $<0.0001$ ( $p_{\text {corrected }}$ $($ all $)<0.05)$ for the " $b$ " terms in the Poisson model), but not for the CST, SFOF, or fornix ( $t$ (all) $<=1.3, p$ (all) $\geq 0.1051$ for the " $a$ " terms and $t($ all $) \geq 2727, p$ (all) $<0.0001$ ( $p_{\text {corrected }}($ all $)<$ $0.05)$ for the " $b$ " terms) (Fig. 6). Adjusting for study site as a covariate did not alter the results.

\section{Discussion}

Our findings indicate that a human-specific haplotype of the FADS gene cluster, which increases the synthesis of $\omega-3$ and $\omega-6$ LC-PUFAs (Ameur et al., 2012), is associated with age-related WM differences from childhood to early adulthood. This finding is consistent with our hypothesis that these LC-PUFAs, such as DHA and AA, are important for human brain WM development. The significant age $\times$ genotype interactions were observed for the cerebral WM tracts globally, and regionally for WM tracts that connect association regions (genu of CC, ILF, IFOF, SLF, uncinate), as found by tractography and TBSS analysis.

The significant age $\times$ genotype interactions for the tractography ILF and IFOF are, to some extent, supported by the significant interaction for the TBSS SS, which contains a major part of their posterior temporal and occipital fibers (Mori et al., 2008). The significant interaction for the tractography IFOF is further supported by the significant interaction for the TBSS EC, which contains a major part of the temporal IFOF (Mori et al., 2008). The interaction for the splenium of CC was significant in the TBSS analysis, but not in the tractography analysis, possibly because the TBSS CC is restricted to its medial section, whereas the tractography CC also included lateral fibers tracing into both hemispheres. Finally, exploratory analyses of the additional TBSS ROIs also indicated significant age $\times$ genotype interactions for the body of CC, thalamocortical, and long corticofugal projection fibers. In contrast, the cinglum displayed normal age-related WM differences independent of FADS haplotype. The cingulum bundle is the last major WM tract to mature (Lebel and Beaulieu, 2011; Kochunov et al., 2012; Peters et al., 2014) and may play a critical role in development of cognitive control and executive functioning (Fjell et al., 2012; Peters et al., 2014). Therefore, in individuals homozygous for the minor allele (associated with lower LC-PUFA concentrations), LC-PUFAs may be allocated to myelination of this bundle, at the expense of other WM tracts, during WM development from childhood into adulthood. However, there was a main effect for overall lower FA values in the cingulum, as well as in the genu of CC and, to a lesser extent, in other WM tracts of minor allele homozygotes, compared with major allele carriers, which suggests that the FADS haplotype affects WM myelination partially independent of the age effect. We note that minor allele homozygotes did display anisotropic WM diffusion in childhood, which indicates that they were able to develop coherent axon bundles and basic myelin sheaths early in development. In sum, our data suggest that $\omega-3$ and $\omega-6$ LCPUFAs are important for cerebral WM myelination from childhood to adulthood.

The mechanisms by which LC-PUFAs affect WM are not yet fully understood. Omega-3 and $\omega-6$ LC-PUFAs are essential components of all cell membranes, including oligodendrocyte membranes, which form the myelin sheaths of axons. Although $\omega-3$ and $\omega$-6 LC-PUFAs have distinct molecular structures and biological effects (Kinsella, 1990), overlapping characteristics of these LC-PUFAs are important for maintaining general cell 
membrane properties, such as membrane "fluidity" (Kinsella, 1990) and membrane cohesion (O’Brien, 1964). These general properties may be important for myelin formation, that is, $\omega$ - 3 and $\omega$ - 6 LC-PUFAs may stimulate oligodendrocyte membrane expansion through "oiling" of the cell membrane fusion machinery (Darios and Davletov, 2006) and may stabilize the myelin membrane through formation of carbon-carbon interactions cross-linking to the opposite membrane layer (O'Brien, 1964). In addition, $\omega$-3 LC-PUFAs have been found to stimulate BDNF protein expression (Wu et al., 2004; Rao et al., 2007), whereas common variation in the BDNF gene has been found to affect WM microstrucure (Tost et al., 2013). Furthermore, $\omega$-3 LCPUFAs have been found to directly stimulate the expression of myelin proteins (Salvati et al., 2008). Thus, specific effects of $\omega$-3 LC-PUFAs as well as general properties of $\omega-3$ and $\omega-6$ LCPUFAs may be involved in healthy WM development.

The FADS haplotype appeared an estimated 255,000 years ago (Ameur et al., 2012), after the lineage split leading to modern humans, which suggests that this haplotype may have provided an evolutionary advantage. This advantage may have involved increased bioavailability of $\omega$-3 and $\omega$-6 LC-PUFAs necessary for healthy brain development (Clandinin et al., 1994; Spector, 2001). There is a relative paucity of data on the role of LC-PUFAs in healthy brain WM development from childhood to adulthood. The principle LC-PUFA in the brain is DHA, comprising 10$20 \%$ of total brain fatty acids and preferentially accumulating in growth cones, synaptosomes, myelin, microsomal, and mitochondrial membranes (McNamara and Carlson, 2006). Bourre et al. (1984) determined in rats that DHA constituted 5.8\% of myelin. In animal data, the estimated half-life turnover time of myelin lipids was $\sim 1-2$ months during active brain development (Smith, 1967) and during adulthood a small portion of brain DHA and AA is replaced daily by unesterified LC-PUFAs in plasma (an estimated 2-8\% and 3-5\%, respectively) (Rapoport et al., 2001). Brain and erythrocyte LC-PUFA levels are positively correlated (McNamara, 2013), and a family study has estimated that polygenes explain interindividual variability in erythrocyte DHA and AA levels by $\sim 71 \%$ and $\sim 53 \%$, respectively (Lemaitre et al., 2008). Total explained variability in the erythrocyte $\omega$-3 index (eicosapentaenoic acid plus DHA) was, to a large extent, explained by heritability (24\%), eicosapentaenoic acid plus DHA intake (25\%), and fish oil supplementation (15\%) (Harris et al., 2012).

It has been proposed that deficiencies of LC-PUFAs in modern humans have compromised healthy brain development and increased the risk for neurodevelopmental psychiatric disorders (Horrobin, 1998). Indeed, decreased levels of LC-PUFAs (in particular DHA and AA) as well as WM abnormalities have consistently been observed in schizophrenia and bipolar disorder, including in medication-naive patients in the early phase of illness (Mahon et al., 2010; McNamara et al., 2010; Walterfang et al., 2011; van der Kemp et al., 2012). The relationship of FADS haplotype to risk for neurodevelopmental psychiatric disorders, such as schizophrenia and bipolar disorder, is not robust (Fallin et al., 2004; Schizophrenia Psychiatric Genome-Wide Association Study (GWAS) Consortium, 2011). Indeed, the factors causing decreased LC-PUFA concentrations in these disorders are likely multifactorial. Nevertheless, because the FADS haplotype significantly influences $\omega$-3 and $\omega$-6 LC-PUFA concentrations (Schaeffer et al., 2006; Ameur et al., 2012), our findings suggest that not only FADS haplotype, but also decreases in these LCPUFA concentrations resulting from other factors may affect brain WM development.
Our data indicate no significant effect of $\omega$-3 and $\omega-6$ LCPUFAs on microstructural WM integrity in late adulthood and old age. LC-PUFAs may not be involved in preservation of myelin integrity, or degenerative processes may override the protective effects of LC-PUFAs on myelin integrity during this age period.

There are some limitations to our study. First, because of a low frequency of minor allele homozygosity (14.5\% in our sample; $13 \%$ in a larger white sample) (Schaeffer et al., 2006) and the recessive effect of this genotype, our study may have been underpowered in the older age ranges. Second, DTI methodologies differed between the two study sites, most notably in MRI magnet strength. However, DTI data of both study sites comprised highresolution images with considerable overlap in their acquisition parameters and postprocessing steps, such as a relatively small voxel size, a sufficiently robust number of diffusion-weighted gradient directions to measure FA (Jones, 2004), use of a weighted least-squares approach for tensor estimation, and an identical set of measured WM tracts, which was complemented by an analysis using one TBSS procedure. Although subjects from $\mathrm{CAMH}$ were on average older than $\mathrm{ZHH}$ subjects, adjusting for study site in the analyses did not alter the results. Third, FA is not specific to myelination (Beaulieu, 2002); therefore, the association between the FADS haplotype and WM microstructure could involve mechanisms other than myelination.

In conclusion, our data indicate that brain WM development is associated with a human-specific haplotype that regulates LCPUFA synthesis and is strongly associated with blood concentrations of $\omega-3$ and $\omega-6$ LC-PUFAs (Ameur et al., 2012). These findings provide further evidence that these LC-PUFAs are involved in myelin formation from childhood to adulthood. In addition, the fact that this haplotype is unique to humans suggests that it may have played a role in prefrontal WM expansion during human evolution (Schoenemann et al., 2005). Furthermore, LC-PUFAs may play an important role in neurodevelopmental disorders that may be unique to humans and in which compromised myelination has been implicated, such as schizophrenia and bipolar disorder.

Further basic and clinical studies are warranted to examine the role of the FADS gene cluster in brain WM myelination, including the molecular pathways through which LC-PUFAs affect WM myelination, with a specific focus on the critical developmental windows herein. These studies may be combined with in vivo measures of peripheral LC-PUFAs (e.g., in erythrocyte membranes), central LC-PUFAs (e.g., in neuronal and glial membranes, through phosphorus magnetic resonance spectroscopy) (Richardson et al., 2001; Yao et al., 2002), and multimodal imaging of WM microstructure/ myelin content to provide a more direct link between LC-PUFAs and WM myelination. Overall, these findings support further investigation of the role of LCPUFAs in brain WM development, which may be of relevance to myelin-related disorders of neurodevelopmental origin.

\section{References}

Ameur A, Enroth S, Johansson A, Zaboli G, Igl W, Johansson AC, Rivas MA, Daly MJ, Schmitz G, Hicks AA, Meitinger T, Feuk L, van Duijn C, Oostra B, Pramstaller PP, Rudan I, Wright AF, Wilson JF, Campbell H, Gyllensten U (2012) Genetic adaptation of fatty-acid metabolism: a humanspecific haplotype increasing the biosynthesis of long-chain omega- 3 and omega-6 fatty acids. Am J Hum Genet 90:809-820. CrossRef Medline

Beaulieu C (2002) The basis of anisotropic water diffusion in the nervous system: a technical review. NMR Biomed 15:435-455. CrossRef Medline

Behrens TE, Woolrich MW, Jenkinson M, Johansen-Berg H, Nunes RG, Clare S, Matthews PM, Brady JM, Smith SM (2003) Characterization and propagation of uncertainty in diffusion-weighted MR imaging. Magn Reson Med 50:1077-1088. CrossRef Medline 
Bourre JM, Pascal G, Durand G, Masson M, Dumont O, Piciotti M (1984) Alterations in the fatty acid composition of rat brain cells (neurons, astrocytes, and oligodendrocytes) and of subcellular fractions (myelin and synaptosomes) induced by a diet devoid of n-3 fatty acids. J Neurochem 43:342-348. CrossRef Medline

Braskie MN, Jahanshad N, Stein JL, Barysheva M, Johnson K, McMahon KL, de Zubicaray GI, Martin NG, Wright MJ, Ringman JM, Toga AW, Thompson PM (2012) Relationship of a variant in the NTRK1 gene to white matter microstructure in young adults. J Neurosci 32:5964-5972. CrossRef Medline

Brauer J, Anwander A, Friederici AD (2011) Neuroanatomical prerequisites for language functions in the maturing brain. Cereb Cortex 21:459-466. CrossRef Medline

Brouwer RM, Mandl RC, Peper JS, van Baal GC, Kahn RS, Boomsma DI, Hulshoff Pol HE (2010) Heritability of DTI and MTR in nine-year-old children. Neuroimage 53:1085-1092. CrossRef Medline

Chiang MC, McMahon KL, de Zubicaray GI, Martin NG, Hickie I, Toga AW, Wright MJ, Thompson PM (2011) Genetics of white matter development: a DTI study of 705 twins and their siblings aged 12 to 29 . Neuroimage 54:2308-2317. CrossRef Medline

Clandinin MT, Jumpsen J, Suh M (1994) Relationship between fatty acid accretion, membrane composition, and biologic functions. J Pediatr 125: S25-S32. CrossRef Medline

Crawford MA, Bloom M, Broadhurst CL, Schmidt WF, Cunnane SC, Galli C, Gehbremeskel K, Linseisen F, Lloyd-Smith J, Parkington J (1999) Evidence for the unique function of docosahexaenoic acid during the evolution of the modern hominid brain. Lipids 34[Suppl]:S39-S47.

Darios F, Davletov B (2006) Omega-3 and omega- 6 fatty acids stimulate cell membrane expansion by acting on syntaxin 3. Nature 440:813-817. CrossRef Medline

Fallin MD, Lasseter VK, Wolyniec PS, McGrath JA, Nestadt G, Valle D, Liang KY, Pulver AE (2004) Genomewide linkage scan for bipolar-disorder susceptibility loci among Ashkenazi Jewish families. Am J Hum Genet 75:204-219. CrossRef Medline

First MB Sr, Gibbon M, Williams JBW (1995) Structured clinical interview for DSM-IV axis I disorders, patient edition (SCID-P). New York: Biometrics Research.

First MB, Spitzer RL, Miriam G, Williams JBW (2001) Structured clinical interview for DSM-IV-TR axis I disorders, non-patient edition (SCID-I/ NP). New York: Biometrics Research, New York State Psychiatric Institute.

Fjell AM, Walhovd KB, Brown TT, Kuperman JM, Chung Y, Hagler DJ Jr, Venkatraman V, Roddey JC, Erhart M, McCabe C, Akshoomoff N, Amaral DG, Bloss CS, Libiger O, Darst BF, Schork NJ, Casey BJ, Chang L, Ernst TM, Gruen JR, et al. (2012) Multimodal imaging of the self-regulating developing brain. Proc Natl Acad Sci U S A 109:19620-19625. CrossRef Medline

Gogtay N, Lu A, Leow AD, Klunder AD, Lee AD, Chavez A, Greenstein D, Giedd JN, Toga AW, Rapoport JL, Thompson PM (2008) Threedimensional brain growth abnormalities in childhood-onset schizophrenia visualized by using tensor-based morphometry. Proc Natl Acad Sci U S A 105:15979-15984. CrossRef Medline

Harris WS, Pottala JV, Lacey SM, Vasan RS, Larson MG, Robins SJ (2012) Clinical correlates and heritability of erythrocyte eicosapentaenoic and docosahexaenoic acid content in the Framingham Heart Study. Atherosclerosis 225:425-431. CrossRef Medline

Hoen WP, Lijmer JG, Duran M, Wanders RJ, van Beveren NJ, de Haan L (2013) Red blood cell polyunsaturated fatty acids measured in red blood cells and schizophrenia: a meta-analysis. Psychiatry Res 207:1-12. CrossRef Medline

Holm S (1979) A simple sequentially rejective multiple test procedure. Scand J Stat 6:65-70.

Horrobin DF (1998) Schizophrenia: the illness that made us human. Med Hypotheses 50:269-288. CrossRef Medline

Jahanshad N, Kochunov PV, Sprooten E, Mandl RC, Nichols TE, Almasy L, Blangero J, Brouwer RM, Curran JE, de Zubicaray GI, Duggirala R, Fox PT, Hong LE, Landman BA, Martin NG, McMahon KL, Medland SE, Mitchell BD, Olvera RL, Peterson CP, et al. (2013) Multi-site genetic analysis of diffusion images and voxelwise heritability analysis: a pilot project of the ENIGMA-DTI working group. Neuroimage 81:455-469. CrossRef Medline

Jenkinson M, Smith S (2001) A global optimisation method for robust af- fine registration of brain images. Med Image Anal 5:143-156. CrossRef Medline

Jones DK (2004) The effect of gradient sampling schemes on measures derived from diffusion tensor MRI: a Monte Carlo study. Magn Reson Med 51:807-815. CrossRef Medline

Kaufman J, Birmaher B, Brent D, Rao U, Flynn C, Moreci P, Williamson D, Ryan N (1997) Schedule for affective disorders and schizophrenia for school-age children-present and lifetime version (K-SADS-PL): Initial reliability and validity data. J Am Acad Child Adolesc Psychiatry 36:980988. CrossRef Medline

Kim YJ, Kim OY, Cho Y, Chung JH, Jung YS, Hwang GS, Shin MJ (2012) Plasma phospholipid fatty acid composition in ischemic stroke: importance of docosahexaenoic acid in the risk for intracranial atherosclerotic stenosis. Atherosclerosis 225:418-424. CrossRef Medline

Kinsella JE (1990) Lipids, membrane receptors, and enzymes: effects of dietary fatty acids. J Parenter Enteral Nutr 14[5 Suppl]:200S-217S.

Kochunov P, Williamson DE, Lancaster J, Fox P, Cornell J, Blangero J, Glahn DC (2012) Fractional anisotropy of water diffusion in cerebral white matter across the lifespan. Neurobiol Aging 33:9-20. CrossRef Medline

Lebel C, Beaulieu C (2011) Longitudinal development of human brain wiring continues from childhood into adulthood. J Neurosci 31:1093710947. CrossRef Medline

Lebel C, Gee M, Camicioli R, Wieler M, Martin W, Beaulieu C (2012) Diffusion tensor imaging of white matter tract evolution over the lifespan. Neuroimage 60:340-352. CrossRef Medline

Lemaitre RN, Siscovick DS, Berry EM, Kark JD, Friedlander Y (2008) Familial aggregation of red blood cell membrane fatty acid composition: the Kibbutzim Family Study. Metabolism 57:662-668. CrossRef Medline

Lencz T, Szeszko PR, DeRosse P, Burdick KE, Bromet EJ, Bilder RM, Malhotra AK (2010) A schizophrenia risk gene, ZNF804A, influences neuroanatomical and neurocognitive phenotypes. Neuropsychopharmacology 35:2284-2291. CrossRef Medline

Lett TA, Chakavarty MM, Felsky D, Brandl EJ, Tiwari AK, Gonçalves VF, Rajji TK, Daskalakis ZJ, Meltzer HY, Lieberman JA, Lerch JP, Mulsant BH, Kennedy JL, Voineskos AN (2013) The genome-wide supported microRNA-137 variant predicts phenotypic heterogeneity within schizophrenia. Mol Psychiatry 18:443-450. CrossRef Medline

Lopez LM, Bastin ME, Maniega SM, Penke L, Davies G, Christoforou A, Valdés Hernández MC, Royle NA, Tenesa A, Starr JM, Porteous DJ, Wardlaw JM, Deary IJ (2012) A genome-wide search for genetic influences and biological pathways related to the brain's white matter integrity. Neurobiol Aging 33:1847.e1-14. CrossRef Medline

Mahon K, Burdick KE, Szeszko PR (2010) A role for white matter abnormalities in the pathophysiology of bipolar disorder. Neurosci Biobehav Rev 34:533-554. CrossRef Medline

Martínez M, Mougan I (1998) Fatty acid composition of human brain phospholipids during normal development. J Neurochem 71:2528-2533. CrossRef Medline

McIntosh AM, Moorhead TW, Job D, Lymer GK, Muñoz Maniega S, McKirdy J, Sussmann JE, Baig BJ, Bastin ME, Porteous D, Evans KL, Johnstone EC, Lawrie SM, Hall J (2008) The effects of a neuregulin 1 variant on white matter density and integrity. Mol Psychiatry 13:1054-1059. CrossRef Medline

McNamara RK (2013) Deciphering the role of docosahexaenoic acid in brain maturation and pathology with magnetic resonance imaging. Prostaglandins Leukot Essent Fatty Acids 88:33-42. CrossRef Medline

McNamara RK, Carlson SE (2006) Role of omega-3 fatty acids in brain development and function: potential implications for the pathogenesis and prevention of psychopathology. Prostaglandins Leukot Essent Fatty Acids 75:329-349. CrossRef Medline

McNamara RK, Jandacek R, Rider T, Tso P, Dwivedi Y, Pandey GN (2010) Selective deficits in erythrocyte docosahexaenoic acid composition in adult patients with bipolar disorder and major depressive disorder. J Affect Disord 126:303-311. CrossRef Medline

Mori S, Oishi K, Jiang H, Jiang L, Li X, Akhter K, Hua K, Faria AV, Mahmood A, Woods R, Toga AW, Pike GB, Neto PR, Evans A, Zhang J, Huang H, Miller MI, van Zijl P, Mazziotta J (2008) Stereotaxic white matter atlas based on diffusion tensor imaging in an ICBM template. Neuroimage 40:570-582. CrossRef Medline

Nordvik I, Myhr KM, Nyland H, Bjerve KS (2000) Effect of dietary advice and n-3 supplementation in newly diagnosed MS patients. Acta Neurol Scand 102:143-149. CrossRef Medline 
O’Brien JS (1964) A molecular defect of myelination. Biochem Biophys Res Commun 15:484-490. CrossRef Medline

O'Donnell LJ, Kubicki M, Shenton ME, Dreusicke MH, Grimson WE, Westin CF (2006) A method for clustering white matter fiber tracts. AJNR Am J Neuroradiol 27:1032-1036. Medline

Paus T, Keshavan M, Giedd JN (2008) Why do many psychiatric disorders emerge during adolescence? Nat Rev Neurosci 9:947-957. CrossRef Medline

Peters BD, Duran M, Vlieger EJ, Majoie CB, den Heeten GJ, Linszen DH, de Haan L (2009) Polyunsaturated fatty acids and brain white matter anisotropy in recent-onset schizophrenia: a preliminary study. Prostaglandins Leukot Essent Fatty Acids 81:61-63. CrossRef Medline

Peters BD, Szeszko PR, Radua J, Ikuta T, Gruner P, DeRosse P, Zhang JP, Giorgio A, Qiu D, Tapert SF, Brauer J, Asato MR, Khong PL, James AC, Gallego JA, Malhotra AK (2012) White matter development in adolescence: diffusion tensor imaging and meta-analytic results. Schizophr Bull 38:1308-1317. CrossRef Medline

Peters BD, Machielsen MW, Hoen WP, Caan MW, Malhotra AK, Szeszko PR, Duran M, Olabarriaga SD, de Haan L (2013) Polyunsaturated fatty acid concentration predicts myelin integrity in early-phase psychosis. Schizophr Bull 39:830-838. CrossRef Medline

Peters BD, Ikuta T, DeRosse P, John M, Burdick KE, Gruner P, Prendergast DM, Szeszko PR, Malhotra AK (2014) Age-related differences in white matter tracts microstructure are associated with cognitive performance from childhood to adulthood. Biol Psychiatry 75:248-256. CrossRef Medline

Rao JS, Ertley RN, Lee HJ, DeMar JC Jr, Arnold JT, Rapoport SI, Bazinet RP (2007) n-3 polyunsaturated fatty acid deprivation in rats decreases frontal cortex BDNF via a 38 MAPK-dependent mechanism. Mol Psychiatry 12:36-46. CrossRef Medline

Rapoport SI, Chang MC, Spector AA (2001) Delivery and turnover of plasma-derived essential PUFAs in mammalian brain. J Lipid Res 42:678685. Medline

Richardson AJ, Allen SJ, Hajnal JV, Cox IJ, Easton T, Puri BK (2001) Associations between central and peripheral measures of phospholipid breakdown revealed by cerebral 31-phosphorus magnetic resonance spectroscopy and fatty acid composition of erythrocyte membranes. Prog Neuropsychopharmacol Biol Psychiatry 25:15131521. CrossRef Medline

Sakuma H, Nomura Y, Takeda K, Tagami T, Nakagawa T, Tamagawa Y, Ishii Y, Tsukamoto T (1991) Adult and neonatal human brain: diffusional anisotropy and myelination with diffusion-weighted MR imaging. Radiology 180:229-233. Medline

Salvati S, Natali F, Attorri L, Di Benedetto R, Leonardi F, Di Biase A, Ferri F, Fortuna S, Lorenzini P, Sanchez M, Ricceri L, Vitelli L (2008) Eicosapentaenoic acid stimulates the expression of myelin proteins in rat brain. J Neurosci Res 86:776-784. CrossRef Medline

Schaeffer L, Gohlke H, Müller M, Heid IM, Palmer LJ, Kompauer I, Demmelmair H, Illig T, Koletzko B, Heinrich J (2006) Common genetic variants of the FADS1 FADS2 gene cluster and their reconstructed haplotypes are associated with the fatty acid composition in phospholipids. Hum Mol Genet 15:1745-1756. CrossRef Medline

Schizophrenia Psychiatric Genome-Wide Association Study (GWAS) Consortium (2011) Genome-wide association study identifies five new schizophrenia loci. Nat Genet 243:969-976. CrossRef Medline
Schoenemann PT, Sheehan MJ, Glotzer LD (2005) Prefrontal white matter volume is disproportionately larger in humans than in other primates. Nat Neurosci 8:242-252. CrossRef Medline

Selivonchick DP, Johnston PV (1975) Fat deficiency in rats during development of the central nervous system and susceptibility to experimental allergic encephalomyelitis. J Nutr 105:288-300. Medline

Smith ME (1967) The metabolism of myelin lipids. Adv Lipid Res 5:241278. Medline

Smith SM, Jenkinson M, Johansen-Berg H, Rueckert D, Nichols TE, Mackay CE, Watkins KE, Ciccarelli O, Cader MZ, Matthews PM, Behrens TE (2006) Tract-based spatial statistics: voxelwise analysis of multi-subject diffusion data. Neuroimage; 31:1487-1505. CrossRef Medline

Spector AA (2001) Plasma free fatty acid and lipoproteins as sources of polyunsaturated fatty acid for the brain. J Mol Neurosci 16:159-165; discussion 215-221. CrossRef Medline

Tost H, Alam T, Geramita M, Rebsch C, Kolachana B, Dickinson D, Verchinski BA, Lemaitre H, Barnett AS, Trampush JW, Weinberger DR, Marenco S (2013) Effects of the BDNF val ${ }^{66}$ met polymorphism on white matter microstructure in healthy adults. Neuropsychopharmacology 38:525532. CrossRef Medline

Trapp BD, Bernsohn J (1978) Essential fatty acid deficiency and CNS myelin: biochemical and morphological observations. J Neurol Sci 37:249266. CrossRef Medline

van der Kemp WJ, Klomp DW, Kahn RS, Luijten PR, Hulshoff Pol HE (2012) A meta-analysis of the polyunsaturated fatty acid composition of erythrocyte membranes in schizophrenia. Schizophr Res 141:153-161. CrossRef Medline

Voineskos AN, O'Donnell LJ, Lobaugh NJ, Markant D, Ameis SH, Niethammer M, Mulsant BH, Pollock BG, Kennedy JL, Westin CF, Shenton ME (2009) Quantitative examination of a novel clustering method using magnetic resonance diffusion tensor tractography. Neuroimage 45:370 376. CrossRef Medline

Voineskos AN, Rajji TK, Lobaugh NJ, Miranda D, Shenton ME, Kennedy JL, Pollock BG, Mulsant BH (2012) Age-related decline in white matter tract integrity and cognitive performance: a DTI tractography and structural equation modeling study. Neurobiol Aging 33:21-34. CrossRef Medline

Walterfang M, Velakoulis D, Whitford TJ, Pantelis C (2011) Understanding aberrant white matter development in schizophrenia: an avenue for therapy? Expert Rev Neurother 11:971-987. CrossRef Medline

Westlye LT, Walhovd KB, Dale AM, Bjørnerud A, Due-Tønnessen P, Engvig A, Grydeland H, Tamnes CK, Ostby Y, Fjell AM (2010) Life-span changes of the human brain white matter: diffusion tensor imaging (DTI) and volumetry. Cereb Cortex 20:2055-2068. CrossRef Medline

Wilkinson GS (1993) The Wide Range Achievement Test (WRAT-3): Administration Manual. Wilmington, DE: Wide Range.

Wu A, Ying Z, Gomez-Pinilla F (2004) Dietary omega-3 fatty acids normalize BDNF levels, reduce oxidative damage, and counteract learning disability after traumatic brain injury in rats. J Neurotrauma 21:1457-1467. CrossRef Medline

Yao J, Stanley JA, Reddy RD, Keshavan MS, Pettegrew JW (2002) Correlations between peripheral polyunsaturated fatty acid content and in vivo membrane phospholipid metabolites. Biol Psychiatry 52:823-830. CrossRef Medline 